\title{
A atual política de acolhimento institucional à luz do estatuto da criança e do adolescente
}

\author{
The current politics of residential care on spot by lightning of the child and adolescent \\ statute
}

\author{
Vanessa Rombola Machado *
}

\begin{abstract}
Resumo:
$\mathrm{O}$ artigo se propõe a apresentar a política de acolhimento institucional pautada nos princípios estabelecidos pela legislação voltada a criança e ao adolescente - o Estatuto da Criança e do Adolescente - abordando as normativas, notadamente o Plano Nacional de Convivência Familiar e Comunitária e as Orientações Técnicas para os serviços de acolhimento para Crianças e Adolescentes, tendo em vista que tais normativas vêm sendo incorporadas pela política de atenção à infância e juventude com as alterações propostas na legislação a partir de 2009 com a chamada Nova Lei de Adoção. Apresenta também uma reflexão sobre a realidade dessas instituições de acolhimento, comumente conhecidas como abrigos. A título de conclusão reflete acerca da importância das alterações legais propostas.
\end{abstract}

Palavras-chave: Acolhimento institucional. Crianças e adolescentes. Serviço social.

\begin{abstract}
:
The article come up with presenting the politics of residential care based on the principles established by legislation backed to children and adolescents - The Child and Adolescent Statute - addressing the normative, notably the National Family and Community and Technical Guidelines for care services for children and adolescents, given that such rules that have been incorporated by the politics of attention to childhood and youth with the proposed changes in legislation from 2009 with the called New Adoption Law. It also presents a reflection on the reality of these host institutions, commonly known as shelters. In conclusion reflects about the importance about legal changes.
\end{abstract}

Keywords: Residential care. Children and adolescents. Social work.

\footnotetext{
* Assistente Social, Mestre em Serviço Social e Política Social pela Universidade Estadual de Londrina UEL/PR. Assistente Social da Secretaria de Administração Penitenciária do Estado de São Paulo. Artigo baseado na dissertação de mestrado da autora. (E-mail: vanessarombola@hotmail.com)
} 


\section{Introdução}

Nos propomos aqui a apresentar a política de acolhimento institucional que vem sendo implantada em nosso país a partir das alterações introduzidas no Estatuto da Criança e do Adolescente - ECA (BRASIL, 2005) pela Lei no 12.010 de 03 de agosto de 2009, conhecida como Nova Lei de Adoção.

Tal política se propõe alterar a forma como as instituições de acolhimento institucional, os assim chamados abrigos, atendem crianças e adolescentes que são colocados sob sua guarda. A partir do Plano Nacional de Promoção, Proteção e Defesa do Direito de Crianças e Adolescentes à Convivência Familiar e Comunitária (BRASIL, 2006) e das Orientações Técnicas para os Serviços de Acolhimento para Crianças e Adolescentes (BRASIL, 2008), aprovadas em 2009 pelo Conselho Nacional dos Direitos da Criança e do Adolescente - CONANDA, os novos parâmetros que norteiam esse atendimento foram estabelecidos e incorporados pela legislação.

Inicialmente apresentamos os princípios e diretrizes que norteiam o ECA, sua estrutura e propostas para a política de atendimento, e em seguida discutimos a realidade dos abrigos e as propostas contidas nas Orientações Técnicas para os Serviços de Acolhimento.

\section{Apresentando o Estatuto da Criança e do Adolescente}

O ECA é uma legislação infra-constitucional, cujo objetivo é criar condições de exigibilidade para o cumprimento dos direitos da criança e do adolescente, rompendo assim com a visão clientelista e repressora vigente em toda a legislação que antecedeu em nosso país; artigos 227 e $228^{1}$ da Constituição Federal. Esta lei tem como alicerce a Doutrina da Proteção Integral, considerada como a primeira legislação infanto-juvenil da América Latina adequada aos princípios da Convenção Internacional sobre os Direitos da Criança. Segundo Torres (2004, p. 241), ela "veio concretizar os novos direitos das crianças e adolescentes, apresentando um caráter inovador e de ruptura com a tradição nacional".

\footnotetext{
${ }^{1} \mathrm{O}$ artigo 228 define que "são penalmente inimputáveis os menores de dezoito anos, sujeitos às normas da legislação especial” (BRASIL, 1988).
} 
O ECA é considerado inovador, pois concebe a criança e o adolescente como seres passíveis de proteção integral por serem indivíduos em desenvolvimento; por isso, têm prioridade absoluta, independente da classe social a que pertençam (SIMÕES, 2009). Inova ainda quando faz referência à forma de atendimento a este segmento, visando à superação de ações assistencialistas, compreendendo-os enquanto sujeitos de direitos. Com a sua promulgação, buscou-se (re)direcionar o olhar da nação para as necessidades inerentes a essa população desprotegida, deixando de lado o pressuposto de reformar e modelar repressivamente as crianças e adolescentes para se preocupar com a sua proteção integral, defendendo seus direitos e buscando erradicar todo e qualquer tipo de violação dos mesmos. Pode-se destacar, então, três avanços significativos conquistados com esta legislação: 1. a criança e o adolescente passaram a ser considerados sujeitos de direitos; 2. tais sujeitos de direitos são reconhecidos como pessoas em condição peculiar de desenvolvimento; 3. como corolário das duas primeiras conjugadas, à criança e ao adolescente é assegurada prioridade absoluta na aplicação desse novo direito.

Em seu artigo 4.ำ, parágrafo único, o ECA estabelece que a garantia de prioridade da criança e do adolescente no atendimento, execução e formulação (de políticas públicas), compreende: primazia de receber proteção e socorro em quaisquer circunstâncias; precedência de atendimento nos serviços públicos ou de relevância pública; preferência na formulação e na execução das políticas sociais públicas; destinação privilegiada de recursos públicos nas áreas relacionadas à proteção à infância e à juventude.

Ao lado dessas medidas específicas que visam a assegurar os direitos da criança e do adolescente nos termos do princípio da proteção integral, o ECA assegura os direitos fundamentais da criança e do adolescente previstos nos artigos 7ำ até o artigo 69: Direito à Vida e à Saúde; Direito à Liberdade, ao Respeito e à Dignidade; Direito à Convivência Familiar e Comunitária (não o Direito à Adoção); Direito à Educação, à Cultura, ao Esporte e ao Lazer;Direito à Profissionalização e à Proteção no Trabalho.

A partir das premissas e princípios aqui elencados, a operacionalização da política de atendimento constituiu-se, desde a sua promulgação, em um grande desafio aos agentes que compõem o Sistema de Garantia de Direitos, isto é, ao conjunto de atores sociais que devem prezar pela proteção integral à criança e ao adolescente, garantindo 
seus direitos: a família, as organizações da sociedade (instituições sociais, associações comunitárias, sindicatos, escolas, empresas), os Conselhos de Direitos, Conselhos Tutelares e as diferentes instâncias do poder público (Ministério Público, Juizado da Infância e da Juventude, Defensoria Pública e Secretaria de Segurança Pública).

Nesse sentido, a Lei prevê, em todas as esferas do governo, a criação dos Conselhos de Direitos da Criança e do Adolescente, órgãos públicos centrais criados para a deliberação e o controle da política de atendimento; modelo, portanto, alternativo à gestão pública tradicional, concebido em termos de uma filosofia de democracia participativa. Cabe a esses Conselhos de Direitos a determinação e fiscalização das políticas e programas destinados à criança ao adolescente e à família, a destinação de recursos para o correto exercício de suas atribuições, bem como a previsão e o direcionamento efetivo de recursos orçamentários aos fundos da criança e do adolescente que, geridos pelos Conselhos, serão utilizados nos termos da Programação e do Plano de Aplicação.

\begin{abstract}
A presença da sociedade civil nos Conselhos, garante aos cidadãos a possibilidade de acesso às informações oficiais e ações públicas. E envolve-os politicamente para uma interlocução constante - ampliando assim os espaços de mediação, negociação e decisão. Esta participação facilita o controle, permitindo que projetos e ações se voltem aos problemas mais coletivos e prioritários e os recursos financeiros sejam efetivamente visíveis e dirigidos à maioria da população, na linha do atendimento às suas necessidades básicas. Os Conselhos reúnem em si portanto, autoridade para desencadear um processo amplo de participação, que democratize a coisa pública. (ISTITUTO DE ESTUDOS ESPECIAIS, 1993, p. 18).
\end{abstract}

Os Conselhos de Direitos possuem, portanto, uma função política relevante, que é a de definir e implementar a Política de Atendimento à Criança e ao Adolescente; seu caráter é deliberativo e controlador.

Previu a Lei ainda a criação dos Conselhos Tutelares, órgãos autônomos e permanentes de natureza não jurisdicional, cujos membros são eleitos pelo voto direto da população e, dada a sua relevância no Sistema de Garantia de Direitos, devem receber da parte do Poder Executivo municipal, que o mantém, toda a infra-estrutura necessária para o desempenho de suas atribuições. Há disposição expressa no ECA sobre a 
obrigatoriedade de constar na lei orçamentária municipal recursos necessários ao seu funcionamento $^{2}$. O Conselho Tutelar, contudo, não tem como atribuição legal a disponibilização direta dos serviços públicos à população infanto-juvenil (saúde, educação, serviço social, previdência, trabalho e segurança); é de sua atribuição reivindicar, junto ao Poder Judiciário, estes serviços públicos à criança e ao adolescente, ou à sua família, quando esses direitos forem violados.

Em termos de acesso à Justiça, o ECA previu a criação de Varas especializadas e exclusivas da infância e juventude em proporcionalidade ao número de habitantes da localidade, cabendo ao Poder Judiciário, em sua proposta orçamentária e em sua execução, criá-las e dotá-las de infra-estrutura - dispondo sobre o seu atendimento, inclusive em forma de plantões -, bem como a provisão de recursos para a manutenção da equipe inter-profissional que assessora o Juiz ${ }^{3}$.

Do ponto de vista da política de atendimento, a Lei procura substituir o assistencialismo filantrópico, vigente até o Código de Menores, por propostas de ações socioeducativas voltadas à garantia da cidadania. Seus princípios estão baseados na cidadania, no bem comum e na condição peculiar de desenvolvimento das crianças e adolescentes: "Esse novo padrão implicou a mudança do modelo de gestão das políticas públicas, reordenando a relação entre os entes federativos, inclusive com a expressa participação da sociedade civil organizada (SIMÕES, 2009, p. 218).

Assim, a execução do ECA insere-se dentro de um quadro programático maior de políticas que podem ser classificadas como políticas sociais. Um olhar panorâmico para esse quadro faz Maria do Carmo Brant de Carvalho (apud ÁVILA, 2000, p. 14 -15) distinguir quatro premissas fundamentais para esse novo desenho da gestão das políticas sociais, nas quais se inserem as políticas voltadas para o atendimento dos direitos da criança e do adolescente:

1. O Direito Social como fundamento da política social. Não há mais espaço para conduzir a política de forma clientelista. Uma pedagogia emancipatória põe acento das fortalezas dos cidadãos usuários dos programas e não mais, tão somente, sobre suas vulnerabilidades. Potencializa talentos, desenvolve a autonomia e fortalece vínculos

\footnotetext{
${ }^{2} \mathrm{ECA}$, art. 134, parágrafo único.

${ }^{3} \mathrm{ECA}$, art. 145, 150.
} 
relacionais capazes de assegurar a inclusão social. Ganham primazia as dimensões ética, estética e comunicativa.

2.Um novo equilíbrio entre políticas universalistas e focalistas. As opções políticas requerem hoje a arte de contemplar universalismo e focalismo. Para responder às demandas das minorias ou àquelas questões mais candentes (como, por exemplo, a luta contra a pobreza). Um exemplo desse enfoque está no Programa Toda Criança na Escola, que, sem descartar a direção universalista, focaliza as crianças que estão fora da escola. Nessa mesma direção, valorizam-se programas que atendam às demandas e necessidades dos grupos castigados pela pobreza ou mais vulnerabilizados na sociedade contemporânea. São exemplos os programas de qualificação dos precariamente inseridos no mercado de trabalho, o crédito e assessoramento para formação de novos microempreendimentos, a transferência monetária (bolsa-escola, renda mínima, etc.), os programas de capacitação de jovens e de erradicação do trabalho infantil entre outros.

3. A transparência nas decisões, na ação pública, na negociação, na participação. A transparência, além de maior profissionalismo, apresenta-se como base de uma ética na prestação dos serviços públicos. É nesse ponto que se encontra incentivo para a implantação efetiva do orçamento participativo, p.ex., em atenção ao Princípio da Publicidade.

4. A avaliação de políticas e programas sociais. A avaliação, e não apenas o planejamento, ganhou centralidade na gestão social. Esperam-se da gestão controles menos burocráticos e mais voltados para medir a eficiência no gasto e a eficácia e efetividade nos resultados.

Estas premissas estão contidas no ECA (na sua parte especial), a qual possui um Título, o Título I, com dois capítulos e 12 artigos, todos integralmente voltados a propor e descrever as ações para a área.

\section{Discutindo a política de atendimento proposta pelo ECA}

A política de atendimento à criança e ao adolescente está estabelecida nos artigos de n. 86 até o de n.97 da Lei, os quais prevêem uma série de ações, denominadas em seu conjunto, de Política de Atendimento dos Direitos da Criança e do Adolescente que, por sua vez, devem ser operadas de forma articulada nas várias esferas do governo.

O art. 86 do ECA apresenta os mecanismos para a garantia e a efetivação dos preceitos estabelecidos no artigo 227 da Constituição Federal de 1988, destacando a importância e a legitimidade das organizações não- governamentais, encaradas de modo paritário com as organizações governamentais, em prol dos direitos da criança e do adolescente (CURY, 2005): “Art. 86. A política de atendimento dos direitos da criança e do 
adolescente far-se-á através de um conjunto articulado de ações governamentais e nãogovernamentais, da União, dos estados, do Distrito Federal e dos municípios" (BRASIL, 2005).

Diante da complexidade e da variedade de ações a ser executada para o atendimento deste segmento, a sistematização em linhas de ações tem função pedagógica, segundo Cury (2005), uma vez que tem por objetivo fazer entender que as pessoas devem ser compreendidas em sua totalidade e complexidade (também nas suas relações, necessidades e prioridades), levando em conta que, nesse processo, deve haver espaço para a garantia de direitos, que só ocorre por meio da efetivação de políticas básicas, sérias e efetivas.

Já no art. 88, o ECA estabelece algumas diretrizes, com o fim de levar à efetivação das linhas de ação, visando sempre ao bem estar da criança e do adolescente:

- Municipalização do atendimento;

- Criação de Conselhos de Direitos nos três níveis governamentais (União, Estados e Municípios), com caráter deliberativo e controlador e de constituição paritária;

- Criação e manutenção de programas específicos observando-se a descentralização político administrativa;

- Manutenção de fundos de direitos da criança e do adolescente vinculados aos respectivos Conselhos de Direitos;

- Integração operacional de órgãos do Poder Judiciário, do Ministério Público, da Defensoria Pública, da Segurança Pública e Assistência Social para o efeito de atendimento ao adolescente, autor de ato infracional;

- Mobilização da opinião pública no sentido de promover a participação efetiva e ampla da sociedade na elaboração e execução da política.

Tais diretrizes foram concebidas como marcos para orientar ações na área e estão organicamente articuladas com as linhas de ação previstas no art. 86; são elas:

- $\quad$ políticas sociais básicas;

- $\quad$ políticas e programas de assistência social, em caráter supletivo, para aqueles que deles necessitem; 
- $\quad$ serviços especiais de prevenção e atendimento médico e psicossocial às vítimas de negligência, maus-tratos, exploração, abuso, crueldade e opressão;

- $\quad$ serviço de identificação e localização de pais, responsável, crianças e adolescentes desaparecidos;

- $\quad$ proteção jurídico-social por entidades de defesa dos direitos da criança e do adolescente;

- políticas e programas destinados a prevenir ou abreviar o período de afastamento do convívio familiar e a garantir o efetivo exercício do direito à convivência familiar de crianças e adolescentes;

- campanhas de estímulo ao acolhimento sob forma de guarda de crianças e adolescentes afastados do convívio familiar e à adoção, especificamente interracial, de crianças maiores ou de adolescentes, com necessidades específicas de saúde ou com deficiências e de grupos de irmãos.

Com políticas básicas articuladas com a educação, a saúde e a moradia, estas ações visam à proteção integral da criança e do adolescente, e enfatizam o atendimento àqueles que vivem em situação de necessidade e, por isso, precisam de serviços de caráter especializados.

Em conformidade com os princípios e as diretrizes estabelecidas, e em cumprimento a elas, o ECA concebe diversas modalidades de programas que devem ser desenvolvidos por entidades de atendimento, governamentais e não-governamentais, os quais são apresentados no art. 90, sendo divididos em programas de proteção e sócioeducativos: Orientação e apoio sócio-familiar; Apoio sócioeducativo em meio aberto; Colocação familiar; Acolhimento institucional; Liberdade assistida; Semi-liberdade; Internação.

Para desenvolverem suas ações, esses programas devem, antes de mais nada, inscrever-se e registrar-se no Conselho Municipal dos Direitos da Criança e do Adolescente, mudança que alterou o foco da organização da política. Se antes o Código de Menores visava à centralização e à fiscalização das decisões na esfera federal, com o ECA o modelo é baseado na horizontalidade, daí a descentralização das ações, a articulação entre as instituições e a participação popular no processo de decisões, coordenação e controle de ações (CURY, 2005). 
Dentre os programas acima apresentados, o acolhimento institucional está indicado no art. 92, cujos princípios são os seguintes:

- $\quad$ preservação dos vínculos familiares e promoção da reintegração familiar;

- integração em família substituta, quando esgotados os recursos de manutenção na família natural ou extensa;

- $\quad$ atendimento personalizado e em pequenos grupos;

- desenvolvimento de atividades em regime de coeducação;

- não-desmembramento de grupos de irmãos;

- $\quad$ evitar, sempre que possível, a transferência para outras entidades de crianças e adolescentes abrigados;

- $\quad$ participação na vida da comunidade local;

- $\quad$ preparação gradativa para o desligamento;

- $\quad$ participação de pessoas da comunidade no processo educativo.

Aqui, o ECA novamente propõe uma grande reformulação na lógica de atendimento, visto que prevê a gradativa extinção dos internatos, orfanatos e instituições que então não ofereciam condições adequadas à formação e ao crescimento das crianças e adolescentes. Nesse contexto, deixa-se de lado o conceito da institucionalização e busca-se “a manutenção do menor na família, buscando oferecer mecanismos de proteção ao indivíduo e do ambiente fundamental de seu desenvolvimento" (MARTINS, 1991, p. 53); daí a preocupação em atender tanto a família quanto a comunidade onde as crianças e os adolescentes estão inseridos. Isso porque o convívio e o apoio da família e/ou da comunidade é elemento integrante na vida de uma criança. Não por acaso, o artigo acima citado dá destaque à reinserção na família de origem ou então o encaminhamento para uma família substituta.

A falta ou a carência de recursos materiais não constitui, segundo o Estatuto da Criança e do Adolescente em seu art. 23, motivo suficiente para o afastamento das crianças e dos adolescentes de suas famílias e a colocação em abrigos, visto que essas famílias devem ser incluídas em programas sociais a fim de propiciar a melhoria das condições socioeconômicas e, dessa forma, garantir o fortalecimento dos laços familiares e a emancipação da família. 
Esse conjunto de previsões legais que então assegura os direitos básicos à vida, à saúde, à educação e à convivência familiar e comunitária mira propiciar a essas crianças e adolescentes todas as oportunidades e facilidades que favoreçam o desenvolvimento físico, mental, moral, espiritual e social, respeitando, assim, a sua condição peculiar - de seres em desenvolvimento - que precisam de atenção, proteção e cuidados especiais. Nesse sentido, essas ações assumem significativa importância, por manter "os elos essenciais para o pleno desenvolvimento da criança, por meio da convivência familiar e comunitária, bem como a responsabilidade primordial dos pais no cuidado dos filhos, cabendo ao Estado prover apoio quando necessário" (RIZZINI, 2004, p.14).

Diante dessa nova concepção, compete ao Estado assumir e oferecer serviços básicos de atendimento, não mais, portanto, segundo critérios permeados pela culpabilização individual e familiar. Com isso, conforme destacado por Cury (2005), alterase a concepção antes adotada pela legislação anterior de situação irregular para uma concepção de proteção integral, como preconizado pela Declaração Internacional dos Direitos da Criança e do Adolescente.

Ao lado desses programas e princípios, o artigo 101 elenca as medidas especificamente protetivas, as quais pressupõem a existência e a manutenção de programas destinados a assegurar tais ações:em caminhamento aos pais ou responsável, mediante termo de responsabilidade; orientação, apoio e acompanhamento temporários; matrícula e frequência obrigatórias em estabelecimento oficial de ensino fundamental; inclusão em programa comunitário ou oficial de auxílio à família, à criança e ao adolescente; requisição de tratamento médico, psicológico ou psiquiátrico, em regime hospitalar ou ambulatorial; inclusão em programa oficial ou comunitário de auxílio, orientação e tratamento a alcoólatras e toxicômanos; acolhimento institucional; inclusão em programa de acolhimento familiar;colocação em família substituta.

Esse artigo legisla ainda sobre o caráter de provisoriedade e de excepcionalidade da medida de acolhimento institucional, através de seu parágrafo único, ao declarar que "o abrigo é medida provisória e excepcional, utilizável como forma de transição para colocação em família substituta, não implicando em privação de liberdade" (BRASIL, 2005). 
Se findados todos os recursos para assegurar as condições da permanência da criança no seio de sua família, ela deve ser acolhida por uma instituição que ofereça atendimento em regime de abrigo, devidamente cadastrada no Conselho Municipal dos Direitos da Criança e do Adolescente e no Conselho Municipal de Assistência Social, a fim de que seus direitos não sejam mais violados.

As medidas específicas de proteção estabelecidas no art. 101 são propostas quando da ameaça ou da violação dos direitos reconhecidos na Lei da Criança e do Adolescente [...] focalizando o Estado enquanto responsáveis por sua proteção [...]. No caso específico do abrigo (medida $\mathrm{VI}$ ), este é definido através do parágrafo único do art. 101 como uma medida provisória e excepcional, portanto, uma opção extrema, embora imprescindível, por ser uma retaguarda para a devida aplicação das medidas (CURY, 2005, p. 325).

Conforme destacado anteriormente, o princípio que norteia a legislação é o da máxima preservação dos laços familiares naturais, o que significa que a colocação em família substituta será realizada por meio de guarda, tutela ou adoção; medida admitida apenas quando imprescindível para o desenvolvimento e o bem-estar integral da criança.

A aplicação das medidas de proteção estão vinculadas ao previsto no artigo 129 do ECA, que diz respeito às medidas pertinentes aos pais ou responsáveis: Encaminhamento a programa oficial ou comunitário de proteção à família; Inclusão em programa oficial ou comunitário de auxílio, orientação e tratamento a alcoólatras e toxicômanos; Encaminhamento a tratamento psicológico ou psiquiátrico; Encaminhamento a cursos ou programas de orientação; Obrigação de matricular o filho e acompanhar sua frequência e aproveitamento escolar; Obrigação de encaminhar criança ou adolescente a tratamento especializado, além de outras medidas de caráter estritamente jurisdicional; Advertência; Perda da guarda; Destituição da tutela; Suspensão ou destituição do poder familiar.

Para melhor afirmar os princípios contidos na Constituição Federal de 1988 e no ECA, buscando estabelecer parâmetros de ação nacionais, foi elaborado um plano de proteção e promoção que contempla o público infanto-juvenil em caráter absolutamente prioritário, submetendo todas as demais políticas públicas a um interesse secundário. 
O Plano Nacional de Promoção, Proteção e Defesa do Direito de Crianças e Adolescentes à Convivência Familiar e Comunitária

No ano de 2006 foi a provado o Plano Nacional de Promoção, Proteção e Defesa do Direito de Crianças e Adolescentes à Convivência Familiar e Comunitária (PNCFC), que visa a valorização da instituição familiar. A partir de proposta apresentada por uma comissão inter-setorial organizada pelo poder público na esfera federal, os Conselhos Nacionais dos Direitos da Criança e do Adolescente e de Assistência Social, respectivamente CONANDA e CNAS analisaram e aprovaram o documento.

A partir da constatação de uma realidade que não conseguia assegurar os direitos das crianças e adolescentes acolhidos institucionalmente, reconheceu-se a necessidade da criação de uma diretriz que ditasse metas e ações relativas à garantia da convivência familiar e comunitária. Inicialmente essa diretriz objetivava estabelecer iniciativas concretas para o reordenamento institucional das instituições de acolhimento, no entanto, percebeu-se que a questão era ainda mais complexa, de modo que passou também a orientar os mecanismos de combate à violação ao direito à convivência familiar e comunitária da criança.

O objetivo principal do Plano foi fazer valer o direito fundamental de crianças e adolescentes crescerem e serem educados no seio de uma família e de uma comunidade, tendo como fundamento a prevenção do rompimento dos vínculos familiares, a qualificação dos atendimentos dos serviços de acolhimento e o investimento para o retorno ao convívio da família, seja ela original ou substituta (BRASIL, 2006).

O documento avançou, sobretudo, no campo do chamado "reordenamento" das instituições que oferecem programas de acolhimento institucional, defendendo a profissionalização dessas entidades e dos cuidadores, e a observância dos dispositivos e princípios do ECA para esse tipo de atendimento. Além disso, propôs a implementação de alternativas não institucionais de acolhimento, como os programas de famílias acolhedoras, no sentido de propiciar a convivência familiar e comunitária, mesmo para as crianças e os adolescentes afastados temporariamente de suas famílias de origem.

Se colocar crianças em entidades de acolhimento institucional era antes prática habitual, hoje em dia há uma defesa universal de que essas instituições devem ser a última e provisória instância de moradia do público infantil e só devem ser utilizadas 
como alternativa, isto é, quando não houver qualquer condição de garantir os direitos dessa população no lar em que vivem.

“A convivência familiar e comunitária é fundamental para o desenvolvimento da criança e do adolescente, os quais não podem ser concebidos de modo dissociado de sua família, do contexto sócio-cultural e de todo o seu contexto de vida." (BRASIL, 2006, p. 29).

Para tanto, é imprescindível que seja concretamente estabelecido o reordenamento institucional, que vise à garantia das condições de sobrevivência, do desenvolvimento social e pessoal, a integridade física e moral e o atendimento individualizado. No dito Plano, o conceito Acolhimento Institucional é usado para designar os programas, antes denominados de abrigo, conforme previsto no ECA. O acolhimento institucional compreende diferentes modalidades de instituição: Abrigo Institucional, Casa Lar e Casa de Passagem. São várias as adequações que as instituições devem implementar, segundo o PNCFC (BRASIL, 2006):

- $\quad$ infra-estrutura adequada ao atendimento de pequenos grupos e semelhante a uma residência normal;

- localização em áreas residenciais e não afastadas da comunidade e da realidade de origem das crianças e adolescentes;

- $\quad$ preservação dos vínculos com a família de origem quando não impedida por ordem judicial;

- $\quad$ articulação e contato com o Poder Judiciário;

- condições adequadas ao pleno desenvolvimento das crianças e adolescentes acolhidos, oferecendo o estabelecimento de relações de afeto e cuidado;

- condições, espaços e objetos pessoais que respeitem a individualidade e o espaço privado de cada criança e adolescente;

- atendimento integrado e adequado às crianças e aos adolescentes com deficiência;

- $\quad$ acolhimento de ambos os sexos e diferentes idades, preservando assim os vínculos entre os grupos de irmãos;

- $\quad$ respeito às normas e orientação para as equipes de trabalho, oferecendo a devida capacitação para o trabalho; 
- $\quad$ estabelecimento e articulação com a rede social de apoio;

- $\quad$ promoção da convivência comunitária utilizando os serviços disponíveis na rede de atendimento a evitar o isolamento social;

- $\quad$ preparação da criança e do adolescente para o processo de desligamento, respeitando assim o caráter excepcional e provisório do regime de abrigo;

- fortalecimento e desenvolvimento da autonomia e a inclusão de adolescentes na comunidade visando a sua inserção no mercado de trabalho, possibilitando-Ihes, ainda, as condições de sobrevivência fora da instituição de acolhimento.

\section{Desvelando a realidade dos abrigos}

O Acolhimento Institucional é definido como atendimento institucional a crianças e adolescentes que tiveram seus direitos violados e que necessitam ser afastados, temporariamente, da convivência familiar. O uso da terminologia "acolhimento institucional" é novo e substitui o termo abrigamento (alteração feita pela Lei no 12.010 de 03 de agosto de 2009); medida excepcional e provisória, pois utilizada como forma de transição, uma vez que visa à reintegração familiar.

Essa modalidade de atenção contida no ECA, busca diferenciar-se da de outros momentos da história, em que crianças e adolescentes viveram em instituições parte de suas vidas. Nesse sentido, o termo "instituição" sugere os múltiplos e possíveis conceitos de institucionalização. Goffman (1974, p. 11), por exemplo, define instituição total "como um local de residência e trabalho onde um grande número de indivíduos em situação semelhante, separados da sociedade mais ampla por considerável período de tempo; levam uma vida fechada e formalmente administrada". Já Bleger (1995, p. 94) utiliza a palavra instituição tendo em vista um conjunto de normas, padrões e atividades agrupadas em torno de valores e funções sociais; muito embora, continua o estudioso, “[...] também se defina como organização, no sentido de uma distribuição hierárquica de funções que se realizam geralmente dentro de um edifício, área ou espaço delimitado $[\ldots]^{\prime \prime}$.

Na passagem da legislação anterior para o ECA já estava posto, entretanto, uma mudança conceitual. Tanto o antigo Centro Brasileiro para a Infância e Adolescência 
(CBIA/SP) quanto o Instituto de Estudos Especiais (IEE/PUC-SP) definiram o abrigo como um lugar que oferece proteção, pois lugar alternativo de moradia provisória dentro de um clima residencial, com um atendimento personalizado, em pequenas unidades, para pequenos grupos. Apontaram ainda que entidade de acolhimento institucional não deveria ser confundida com albergue, uma vez que este último é um lugar que, embora ofereça proteção, na maioria das vezes destina-se para pernoite, banho e alimentação provisórios, para famílias itinerantes (INSTITUTO DE ESTUDOS ESEPCIAIS,1993).

O termo acolhimento institucional veio, nesse sentido, alterar as concepções anteriores. São instituições que devem oferecer programas de abrigo e atender crianças e adolescentes que tenham tido seus direitos violados e que, em razão disso, necessitam ser temporariamente afastados da convivência de suas famílias. Funcionam, de fato, como residência provisória, na qual as crianças permanecem até o retorno ao seu lar de origem ou em caso de impossibilidade, até serem colocadas em família substituta (SILVA, 2004).

Nossas crianças estão cercadas pela violência estrutural, entendida como a violência do comportamento, e se aplica tanto às estruturas organizadas e institucionalizadas pela família como aos sistemas econômicos, culturais e políticos que conduzem à opressão de determinadas pessoas, às quais se nega vantagens da sociedade, tornando-as, por isso, mais vulneráveis ao sofrimento e à morte. Essas estruturas determinam igualmente a recusa pelas práticas de socialização, o que leva os indivíduos a aceitar ou a infligir o sofrimento, de acordo com o papel que desempenham (BOULDING apud CRUZ NETO; MOREIRA, 1999). Tal violência vem se perpetuando ao longo das décadas e não se tem perspectivas de mudança tal é a ineficiência das políticas públicas existentes.

Assim, a sociedade vivencia a violência estrutural, sobretudo as famílias vítimas de vulnerabilidade social ${ }^{4}$, econômica, cultural e política, o que concorre para a sua exclusão social, e que se acentua com a falta de políticas públicas. Nesse contexto, as crianças e adolescentes, em situação de risco e vulnerabilidade, tornam-se as principais vítimas (CRUZ NETO; MOREIRA, 1999).

\footnotetext{
${ }^{4}$ Vulnerabilidade refere-se aos grupos ou indivíduos mais atingidos pelos efeitos das desigualdades socioeconômicas (RIZZINI, NAIFF; BAPTISTA, 2006).
} 
Considerando as diversas transformações ocorridas na organização familiar como as situações de risco e violência, o descaso das políticas públicas e todas as facetas do ambiente comunitário, cultural, social, econômico e político em que as famílias estão inseridas, não se pode aqui deixar de ponderar o aspecto coletivo, para então entender as demandas latentes de cada indivíduo.

Oliveira (2007) assinala que nossa tradição cultural e legal trata a infância como um período de desenvolvimento da pessoa com vistas ao estágio da vida adulta. Esse período da vida é, de fato, demarcado pela biologia, mas é inegável a marca peculiar de cada sociedade e cultura. A autora ressalta que não podemos imaginar que todas as crianças de seis anos são iguais, pois cada uma viveu esse tempo de sua maneira, dentro dos parâmetros de seu contexto de vida social e comunitária. Sob essa perspectiva, é possível compreendermos a infância como uma construção social, isto é, perceber a criança como um ator social ativo, que influencia e é influenciado pelo meio social em que vive.

Em relação ao acolhimento institucional, pode-se afirmar que são as mais variadas situações que acarretam a institucionalização das crianças e adolescentes; cada uma delas vivencia, dentro do abrigo, os mais diversos momentos e expectativas: umas esperando o retorno para família biológica e outras aguardando a colocação em famílias substitutas ou com situação a ser ainda definida judicialmente. Nesses, as entidades podem ser classificadas a partir do seu tamanho e capacidade de atendimento, como também pelo tempo (a princípio) de permanência da criança/adolescente e pela especialização do atendimento oferecido.

\section{As entidades de acolhimento institucional}

Os preceitos e princípios norteadores que determinam como deve ocorrer o atendimento na modalidade de acolhimento institucional estão expostos no artigo 92 do ECA (BRASIL, 1990), já apresentado, e no Plano Nacional de Promoção, Proteção e Defesa do Direito de Crianças e Adolescentes à Convivência Familiar e Comunitária.

Os programas de acolhimento institucional deveriam evitar especializações e atendimentos exclusivos a determinadas parcelas da população infanto-juvenil, como adotar faixas etárias muito estreitas, atender exclusivamente portadores de necessidades especiais ou de HIV, dentre outros exemplos. A atenção especializada, quando necessária, 
deve ser realizada por meio da articulação com outros serviços públicos (ou seja, com a rede de serviços) e/ou a partir de pequenas adaptações no espaço e na organização do abrigo, como aconteceria em uma residência comum.

Para Simões $(2009$, p. 251) o atendimento a crianças e adolescentes deve ser embasado no PIA - Plano Individual de Atendimento, que se assenta num "estudo social e pessoal nos procedimentos de elaboração do acolhimento (atendimento inicial) e tem como requisito básico o diagnóstico polidimensional, por meio de intervenções técnicas" a crianças, adolescentes e suas famílias nas mais diferentes e abrangentes áreas (social, saúde, jurídica, psicológica e pedagógica, entre outras), a partir do estabelecimento de metas de ações e atendimento, que devem ser reavaliadas pelo menos semestralmente e mediante informação à autoridade judicial competente.

Em relação ao processo de reintegração familiar, a Associação Brasileira Terra dos Homens, em sua publicação denominada Do Abrigo a Família (ASSOCIAÇÃO BRASILEIRA TERRA DOS HOMENS, 2002), destaca que esse processo deveria começar no momento do acolhimento. Para tanto, a entidade deveria contar com profissionais que pudessem desenvolver um trabalho de aproximação com a família de origem e outras pessoas que convivessem com a criança e, assim, conhecessem (através de entrevistas, visitas domiciliares, observação da relação entre a família e a criança, a comunidade) os motivos do abrigamento, levantando-se perspectivas e alternativas para que a criança pudesse voltar para a família. Isso significa que todo esse processo exige um investimento não só em torno das famílias, bem como em torno da criança.

Gulassa (2005) assinala outras ações bem sucedidas no trabalho com as famílias: preparação dos funcionários para maior aceitação e acolhimento dos familiares; maior flexibilidade nos horários de visitas; almoço dominical com e para os familiares; saídas das crianças e adolescentes para finais de semana com os familiares; telefonemas para a família e destas para seus filhos; ida a espaços recreativos (parque, teatro, cinema, etc.) com as famílias, crianças, adolescentes e/ou profissionais do abrigo; reuniões com realizações de gincana, oficinas de pipas, etc. para pais e filhos e para a discussão de temas apontados pela família; trabalho de mediação com profissionais especializados para reaproximação entre os familiares e seus filhos; participação dos familiares nas reuniões da escola do filho; capacitação dos profissionais para lidar com a violência 
doméstica; supervisão para melhoria do trabalho com as famílias; preparação para a construção de uma rede composta por famílias; assistência jurídica para os familiares; acompanhamento pós-desabrigamento por seis meses.

O acolhimento institucional não é necessariamente "bom ou mau", já que sua aplicação, quando necessário, deve ser, de fato, uma medida de proteção provisória. Por isso, o contexto do acolhimento institucional deve favorecer o desenvolvimento da criança, o que implica pensar num contexto de cuidado e proteção, mas também e concomitantemente, num contexto educativo. É importante que a entidade de acolhimento não seja concebida como um local de exclusão, mas sim como espaço que proporcione o desenvolvimento de crianças e adolescentes que ali permanecem, independentemente do tempo.

Não por acaso, Arpini e Quintana (2003) ressaltam que é relevante repensar, recuperar e investir no universo institucional dessas entidades, superando os estigmas que acompanham a realidade das instituições como lugar do "fracasso", permitindo que o mesmo seja visto como um local de possibilidades, de acolhimento, de afeto e proteção. Mas para se alcançar os ideais acima propostos, as instituições deveriam assemelhar-se, segundo Mello (2004) a um lar comum, cujo atendimento deveria ocorrer em pequenos grupos, de no máximo vinte e cinco crianças por entidade.

Segundo Oliveira (2001) há uma grande heterogeneidade na realidade de atendimento nas entidades de acolhimento institucional, que não é fácil de ser conhecida em sua totalidade. As próprias Varas da Infância e Juventude não conseguem manter registros fidedignos sobre a quantidade de crianças que vivenciam tal realidade, por uma série de motivos: não há dados precisos sobre o número de entidades de acolhimento institucional que existem no País, o número de crianças e adolescentes atendidos e nem dados sobre a adequação das ações dessas instituições ao ECA.

Weber (1995) confirmou a falta de dados sistematizados sobre as crianças institucionalizadas no estado do Paraná e efetuou, em 1990, um levantamento a esse respeito, enfatizando a necessidade da continuidade desses mapeamentos. Em outro estudo, Weber (2002) objetivou identificar os sentimentos das crianças e adolescentes acolhidos institucionalmente e sem vínculo familiar em relação a seus pais biológicos e suas expectativas quanto ao futuro. A autora pretendia entrevistar todas as crianças 
institucionalizadas de Curitiba, mas por ter tido dificuldades de acesso às instituições, colheu dados de 76 delas. Segundo a autora a maioria das crianças e adolescentes quando questionadas sobre sua família de origem e as dificuldades financeiras apresentou respostas de conotação ambivalente; quanto às expectativas em relação ao futuro, mostrou um forte desejo de construir vínculos afetivos duradouros.

A Secretaria do Estado da Criança e Juventude do Paraná lançou a publicação intitulada de Acolhimento Institucional no Paraná: desvelando a realidade em 2007 (LAZZARINI, 2007), que destaca a existência de 285 abrigos, distribuídos em 154 municípios, atendendo um total de 3786 crianças e adolescentes. Já a pesquisa realizada na cidade de São Paulo, a partir do Projeto Integrado de Pesquisa intitulado "Família de crianças e adolescentes abrigados: quem são, como vivem, o que pensam, o que desejam", vinculado a PUC/SP e publicado em 2008 (FÀVRO, VITALE, BAPTISTA, 2008), traça o perfil das famílias dos abrigados, e indica a existência de 49 abrigos, contabilizando 94 crianças e adolescentes atendidos.

Em 2003, numa perspectiva mais abrangente, o Instituto de Pesquisas Econômicas Aplicadas (IPEA) iniciou o Levantamento Nacional dos Abrigos para Crianças e Adolescentes. A pesquisa, realizada através de questionários (SILVA, 2004), envolveu inicialmente 670 instituições e programas de acolhimento institucional de todo o país que recebiam recursos da Rede de Serviços de Ação Continuada (Rede SAC) da Secretaria de Assistência Social do Ministério do Desenvolvimento Social e Combate à Fome, destinados à manutenção do atendimento de crianças e adolescentes. O levantamento teve por objetivo conhecer as características, estrutura de funcionamento e serviços prestados, visando à melhoria do atendimento às crianças e adolescentes, e ainda conhecer o perfil das crianças e adolescentes que se encontram acolhidos institucionalmente. Dentre alguns resultados previamente apresentados, chamou a atenção o desconhecimento do governo federal a respeito dessas instituições, para as quais repassa verbas.

A pesquisa do IPEA constatou que o custo médio-mês por criança/adolescente acolhida em entidades públicas é de $\mathrm{R} \$ 508,14$; já em entidades de acolhimento institucional não-governamental é de $R \$ 365,51$, ou seja, um custo $40 \%$ superior. Dentre os fatores que poderiam justificar a diferença de custo entre as entidades de acolhimento 
governamentais e não-governamentais, pode-se destacar número médio de crianças e adolescentes atendidos por entidade; as diferenças de remuneração da equipe de profissionais da entidade, lembrando que os trabalhadores governamentais, na maioria servidores públicos, reúnem mais vantagens sobre o salário base em comparação aos trabalhadores das entidades não-governamentais; a maior incidência de trabalho voluntário nas entidades não-governamentais e as diferentes atividades e atendimentos oferecidos às crianças e aos adolescentes (SILVA, 2004). Acrescenta a autora que não é pertinente realizar uma análise de custo comparativa entre experiências que muitas vezes apresentam características muito distintas, devido à própria especificidade de cada programa/entidade.

\section{As Orientações Técnicas para os Serviços de Acolhimento para Crianças e Adolescentes}

Aprovada em 18 de Junho de 2009 pelo Conselho Nacional de Assistência Social e pelo Conselho Nacional dos Direitos da Criança e do Adolescente, as Orientações Técnicas para os Serviços de Acolhimento para Crianças e Adolescentes têm por objetivo estabelecer orientações metodológicas e parâmetros para o funcionamento das entidades que ofereçam acolhimento a crianças e a adolescentes, de modo a cumprir os preceitos estabelecidos pelo ECA (proteção e sujeitos de direitos), que então visa o fortalecimento dos vínculos familiares e comunitários, o desenvolvimento de potencialidades e a conquista de maior grau de independência individual e social das crianças e adolescentes atendidos, assim como o empoderamento de suas famílias.

A estruturação de tais serviços deve estar embasada nos seguintes princípios:

- Excepcionalidade do afastamento do convívio familiar: garantia do convívio familiar e comunitário, e garantia de que o afastamento do contexto familiar seja uma medida excepcional, aplicada quando a situação represente risco grave à integridade física e psíquica;

- Provisoriedade do afastamento do convívio familiar: quando ocorrer o afastamento da criança e do adolescente do convívio social e comunitário, deve-se realizar ações que visem, no menor tempo possível, o retorno ao convívio familiar, prioritariamente na família de origem e, excepcionalmente, em família substituta. É necessário ressaltar que a reintegração familiar da 
criança e do adolescente deve ocorrer em tempo inferior a 2 anos, e que a permanência em tempo superior deve ter caráter extremamente excepcional, destinada apenas a situações específicas;

- Preservação e fortalecimento dos vínculos familiares e comunitários: busca pela preservação e fortalecimento dos vínculos familiares e comunitários;

- Garantia de acesso e respeito à diversidade e à não discriminação: todas as crianças e adolescentes que necessitarem de acolhimento institucional têm a garantia de atendimento, sem discriminação (de qualquer origem) a elas e a suas famílias, evitando assim as especializações e atendimentos específicos (ex: atendimento exclusivo a crianças com deficiência), que devem ocorrer apenas em situações de extrema excepcionalidade. Esses serviços devem ainda preservar a diversidade cultural e valorizar a cultura de origem da criança e do adolescente.

- Oferta de atendimento personalizado e individualizado: as ações desenvolvidas dentro dos serviços de acolhimento deverão ser de qualidade, condizentes com os direitos e as necessidades físicas, psicológicas e sociais da criança e do adolescente, tendo respeito à individualização, ao atendimento a pequenos grupos, com garantia de espaços privados, objetos pessoais e registros (até fotográficos) sobre a história de vida e desenvolvimento de cada criança e adolescente.

- Garantia de liberdade de crença e religião: os serviços de acolhimento devem respeitar a crença e religião de cada criança e adolescente, propiciando ainda mecanismos de acesso para que possam satisfazer suas necessidades de vida religiosa e espiritual, viabilizando, assim, o acesso às atividades de sua religião, bem como o direito de não participar de atos religiosos e/ou recusar instrução ou orientação religiosa que não Ihe seja significativa.

- Respeito à autonomia da criança, do adolescente e do jovem: todas as decisões a respeito da vida de crianças e adolescentes acolhidas institucionalmente devem levar em consideração a sua opinião, garantia do direito à escuta e respeito às suas opiniões. 
O documento destaca ainda que o afastamento da criança e do adolescente de seu convívio familiar deve ocorrer mediante recomendação técnica, realizado por equipe interdisciplinar, visando, através do diagnóstico, subsidiar a decisão tanto da Justiça da Infância quanto do Ministério Público. A fim de assegurar o bem estar e a segurança da criança e do adolescente que esse estudo diagnóstico é proposto; é efetuada não só uma criteriosa avaliação dos riscos a que estão submetidos, como também são checadas as condições familiares para a superação das violações existentes e potencialidades para o provimento de proteção e de cuidados. Esse estudo deve incluir todas as pessoas envolvidas diretamente com a criança e com o adolescente. $O$ documento também põe em destaque a necessidade de avaliar se na família extensa ou na comunidade há pessoas significativas para a criança e o adolescente que possam, por ventura, se responsabilizar por elas, antes da opção pelo acolhimento institucional.

As Orientações Técnicas para os Serviços de Acolhimento para Criança e Adolescente determinam ainda que as entidades que oferecem serviços de acolhimento institucional devem elaborar um projeto político-pedagógico que vise qualidade no serviço prestado, contemplando os seguintes aspectos: 1 . Infra-estrutura física que garanta espaços privados e adequados ao desenvolvimento da criança e do adolescente (com espaço físico aconchegante e seguro, com arquitetura semelhante ao de residências, localizando-se em áreas residenciais, visando, assim, a preservação da privacidade e individualidade, com espaços específicos para guardar os objetos pessoais, devendo ser evitado o uso coletivo de roupas e demais artigos de uso pessoal. Recomenda-se ainda que, em cada quarto, sejam acolhidas até 4 crianças/adolescentes, não ultrapassando 6 por quarto); 2. Ambiente e Cuidados Facilitadores do Desenvolvimento (psicossocial das crianças e adolescentes); 3 . Atitude receptiva e acolhedora, sobretudo, no momento da chegada da criança/adolescente (com apresentação das dependências, de outras crianças e adolescentes que lá estiverem abrigadas, bem como dos educadores/cuidadores; 4. Não-desmembramento de grupos de crianças/adolescentes com vínculos de parentesco (não separação de crianças e adolescentes com vínculos de parentesco e afetivos); 5. Relação afetiva e individualizada com cuidadores (construção de relação afetiva estável entre cuidador/educador e criança/adolescente); 6. Definição do papel e valorização dos cuidadores/educadores; 7. 
Organização de registros sobre a história de vida e desenvolvimento de cada criança/adolescente (construção e organização de prontuários que conste anamnese e motivo do acolhimento, com registros semanais do acolhido, contendo relato sintético da rotina e situação de saúde, bem como registro fotográfico do período em que esteve na entidade); 8. Preservação e fortalecimento da convivência comunitária (a criança e o adolescente devem participar da vida diária da comunidade e ter oportunidade de construir laços de afetividade significativos); 9. Desligamento gradativo (a entidade de acolhimento institucional deve promover o desligamento gradativo tanto da criança e do adolescente quanto dos cuidadores/educadores, mantendo, sempre que possível, contato posterior ao desligamento).

As Orientações Técnicas também destacam a necessidade de um trabalho social com as famílias de origem das crianças e adolescentes acolhidos institucionalmente, a partir de atividades que os envolvam e medidas para a preservação e fortalecimento dos vínculos familiares, como a flexibilização de visitas a instituição de acolhimento, se necessário. A intervenção profissional junto à família deve levar em conta o conhecimento dos motivos que levaram à retirada da criança ou do adolescente do lar de origem, para o desenvolvimento de ações pró-ativas. Com relação ao atendimento dessas crianças e adolescentes, o documento especifica que as entidades de acolhimento institucional devem investir na capacitação e acompanhamento dos cuidadores/educadores, que deve ser dividida em capacitação introdutória, capacitação prática e formação continuada. A necessidade de serem acompanhadas por parte da equipe da entidade de acolhimento durante o período de adaptação, bem como o encaminhamento de relatórios com periodicidade (mínima) semestral à Justiça da Infância e da Juventude, com vistas a subsidiar o acompanhamento judicial, são outros dois aspectos enfatizados pelo documento. No caso de a equipe técnica da entidade de acolhimento reconhecer a ausência de indícios para o retorno familiar, o documento determina que ela deve solicitar, mediante relatório circunstanciado, intervenção da autoridade judicial para a destituição do poder familiar e conseqüente encaminhamento para família substituta.

O grande avanço deste documento está relacionado ao estabelecimento de parâmetros de funcionamento das entidades de acolhimento institucional, os quais 
devem oferecer cuidados e condições favoráveis ao desenvolvimento saudável de crianças e adolescentes, visando à reintegração à família de origem ou, na sua impossibilidade, o encaminhamento para família substituta. Determina ainda que os serviços podem ser ofertados em diferentes modalidades:

- Abrigos Institucionais: atende na faixa etária de 0 a 18 anos de idade, sem distinção de faixa etária ou sexo (desde que o município tenha um abrigo geral de atendimento, pode-se criar abrigo para atendimento de algumas especificidades, como exemplo atendimento a adolescentes grávidas), atendendo no máximo 20 crianças e adolescentes, estando localizado em áreas residenciais com padrão arquitetônico semelhante a uma residência comum. Estabelece a necessidade de turno fixo para os educadores e de equipe mínima, composta por um coordenador (com grau superior e experiência neste cargo), um assistente social e um psicólogo (para o atendimento de até 20 crianças e adolescentes, com carga horária de trabalho mínima de 30 horas semanais); dois cuidadores/educadores por turno para cada 10 crianças e adolescentes (podendo aumentar o número se houver crianças menores de um ano ou deficientes). Recomenda que o espaço físico tenha quartos (com até quatro crianças por quarto), sala de estar e de jantar, espaço físico para estudos, banheiro, cozinha, área de serviço, área externa, sala da equipe técnica, sala da coordenação e espaço para realização de reuniões;

- Casas-Lares: Realiza o atendimento de no máximo 10 crianças e adolescentes, estipula a necessidade da presença de um educador ou cuidador residente, podendo ser casal;

- Famílias Acolhedoras;

- Repúblicas: atendimento a jovens de 18 a 21 anos de idade, realizado de acordo com o sexo e de, no máximo, 6 jovens por república. 


\section{Considerações finais}

Neste trabalho procuramos apresentar o ECA, suas propostas de alterações e desdobramentos no que diz respeito ao acolhimento institucional de crianças e adolescentes, com vistas a buscar uma melhor compreensão da política para a área.

Também apresentamos o Plano Nacional de Promoção, Proteção e Defesa do Direito de Crianças e Adolescentes à Convivência Familiar e Comunitária (PNCFC), que visa a valorização da instituição familiar, por meio de diretrizes, metas e ações relativas à garantia da convivência familiar e comunitária. Com esse documento, podemos constatar que a política de atendimento a criança e ao adolescente propõe que o Acolhimento Institucional seja uma medida excepcional que deve ocorrer quando os mesmos tiveram seus direitos violados, pelas mais diversas situações e, por isso, necessitam ser temporariamente afastados da convivência familiar.

Matéria de discussão ainda recente, o documento intitulado Orientações Técnicas para os Serviços de Acolhimento para Crianças e Adolescentes, estabelece parâmetros para o funcionamento das entidades de acolhimento e orientações metodológicas para a sua atuação. A partir dele, ainda pouco aplicado pelas instituições e pelos profissionais que atuam na área, espera-se o estabelecimento dos parâmetros de qualidade para as instituições de acolhimento institucional. Esse conjunto de documentos e leis visa a proteção da criança e do adolescente, sendo que é nele que tem origem a concepção desses sujeitos como sujeitos de direitos.

\section{Referências}

ARPINI, D. M.; QUINTANA, A. M. Identidade, família e relações sociais em adolescente de grupos populares. Revista Estudos de Psicologia, Campinas, v. 20, n. 1, p. 27-36, jan./abr. 2003.

ASSOCIAÇÃO BRASILEIRA TERRA DOS HOMENS. Do abrigo à família. Rio de Janeiro: Booklink, 2002. (Série em Defesa da Convivência Familiar e Comunitária).

ÁVILA, C. Gestão de projetos sociais. 2. ed. São Paulo: AAPCS, 2000.

BLEGER, J. Temas de psicologia: entrevistas e grupos. São Paulo: Martins Fontes, 1995.

BRASIL. Conselho Nacional dos Direitos da Criança e do Adolescente e Conselho Nacional de Assistência Social. Orientações técnicas para os serviços de acolhimento para crianças 
e adolescentes. 2008. Disponível em:

$<$ http://portal.mj.gov.br/sedh/conanda/documentos/orienta\%C3\%A7\%C3\%B5es_acolhim ento_consulta_publica.pdf.>. Acesso em: 4 maio 2010.

BRASIL. Constituição da República Federativa do Brasil de 1988. Disponível em: <http://www.planalto.gov.br/ccivil_03/constituicao/constitui\%C3\%A7ao.htm>. Acesso em: Acesso em: 10 jan. 2009.

BRASIL. Lei Federal n. 8.069, de 13 de julho de 1990. Estatuto da Criança e do Adolescente. Brasília: Senado Federal, 2005.

BRASIL. Ministério do Desenvolvimento Social e Combate à Fome. Plano nacional de promoção, proteção e defesa do direito da criança e do adolescente à convivência familiar e comunitária. Brasília: CONANDA/ CNAS, 2006.

CRUZ NETO, O.; MOREIRA, M. R. A concretização de políticas públicas em direção à prevenção da violência estrutural. Ciência e Saúde Coletiva, Rio de Janeiro, v. 4, n. 1, p. 53-69, 1999. Disponível em: <www.scielo.br/scielo>. Acesso em: 10 jan. 2009.

CURY, Munir. Estatuto da criança e do adolescente comentado: comentários jurídicos e sociais. 7 ed. São Paulo: Malheiros, 2005.

FÁVERO, E.;VITALE, M.A.F.; BAPTISTA, M.V. Famílias de crianças e adolescentes abrigados: quem são, como vivem, o que pensam, o que desejam. São Paulo,Paulus, 2008.

GOFFMAN, E. Manicômios, prisões e conventos. São Paulo: Perspectiva, 1974.

GULASSA, M. L. C. R. (Coord.). O abrigo como possibilidade. São Paulo: Instituto Camargo Corrêa, 2005. (Relatório de Sistematização de Mesas de Trabalho).

INSTITUTO DE ESTUDOS ESPECIAIS - IEE. CENTRO BRASILEIRO PARA A INFÂNCIA E ADOLESCÊNCIA. Trabalhando abrigos. São Paulo: Forja, 1993. Cadernos de Ação.

LAZZARINI, V. (Coord.) Acolhimento institucional no Paraná: desvelando a realidade. Conselho Estadual dos Direitos da Criança e do Adolescente do Paraná. CEDCA/PR, Curitiba, 2007.

MACHADO, V. R. A. Percepção dos atores do sistema de garantia de direitos sobre à casa do menor de Dracena-SP. 2010. 131 f. Dissertação (Mestrado em Serviço Social e Política Social) - Universidade Estadual de Londrina, Londrina, 2010.

MARTINS, J. de S. (Org.). O massacre dos inocentes: a criança sem infância no Brasil. São Paulo: Hucitec, 1991.

MELLO, S. G. O ambiente físico no qual vivem crianças e adolescentes em situação de abrigo. In: . O direito à convivência familiar e comunitária: os abrigos para crianças e adolescentes no Brasil. Brasília: IPEA/CONANDA, 2004. p. 135-167. 
OLIVEIRA, R. C. S. (Coord.). Quero voltar para casa: o trabalho em rede e a garantia do direito à convivência familiar e comunitária para crianças e adolescentes que vivem em abrigos. São Paulo: AASPTJ/SP, 2007. p. 152-229.

OLIVEIRA, R. C. S. Crianças e adolescentes (des) acolhidos: a perda da filiação no processo de institucionalização. 188 f. Dissertação (Mestrado em Serviço Social) - Pontifícia Universidade Católica de São Paulo, São Paulo, 2001.

RIZZINI, I. A institucionalização de crianças no Brasil: percurso histórico e desafios do presente. Rio de Janeiro: PUC, 2004.

RIZZINI, I.; NAIFF, L.; BAPTISTA, R. Acolhendo crianças e adolescentes: experiências de promoção de direito à convivência familiar e comunitária no Brasil. São Paulo: Cortez, 2006.

SÃO APULO. Secretaria Municipal de Assistência Social. Reordenamento de abrigos infanto-juvenis da cidade de São Paulo: construção da política interinstitucional de defesa dos direitos de convivência familiar e comunitária das crianças e adolescentes. São Paulo: SMAS, 2004.

SILVA, E. R. A. (Coord.). O direito à convivência familiar e comunitária: os abrigos para crianças e adolescentes no Brasil. Brasília: IPEA/CONANDA, 2004.

SIMÕES, C. Curso de direito do serviço social. 3. ed. São Paulo: Cortez, 2009.

TORRES, M. J. C.. A política municipal de atenção à criança e ao adolescente no município de Belém: uma breve incursão no período de 1993 a 2003. In: NEVES, R. H.; QUINTELA, R.; CRUZ, S. A reinvenção do social: poder popular e política de assistência em Belém: 19972004. Belém: Paka-Tatu, 2004.

WEBER, L. N. D. Laços de ternura: pesquisas e histórias de adoção. 2. ed. Curitiba: Santa Mônica, 2002.

WEBER, L. N. D; KOSSOBUDZKI, L. H. M. Filhos da solidão: institucionalização, abandono e adoção. Curitiba: Governo do Estado do Paraná, 1995. 